\title{
A alavanca que move o mundo: o discurso da mídia de negócios sobre o capitalismo empreendedor
}

\author{
The lever that moves the world: the business media discourse on entrepreneurial capitalism
}

\author{
Alessandra Mello da Costa ${ }^{1}$ \\ Denise Franca Barros ${ }^{2}$ \\ Paulo Emílio Matos Martins ${ }^{3}$
}

\begin{abstract}
Resumo
Utilizando-se da perspectiva da teoria social do discurso de Norman Fairclough (2001), tem-se por objetivo identificar e discutir possíveis implicações nas relações de trabalho contemporâneas da criação e disseminação do conceito de "empreendedorismo" pelas revistas de negócios. A suposição que norteia este estudo é a de que o discurso utilizado vincula - de forma acrítica e sem questionamentos - o tema "empreendedorismo" a crescimento, desenvolvimento e enriquecimento das organizações e dos indivíduos que nelas trabalham, elegendo e naturalizando o capitalismo de mercado como único modelo possível de desenvolvimento socioeconômico. Para alcançar o objetivo proposto, este estudo baseia-se no método da análise crítica do discurso (ACD) e concentra seu foco no material publicado nas revistas de negócios brasileiras Você S/A Exame, Carta Capital e HSM Management, no período de março de 2004 a abril de 2009, totalizando 112 reportagens e 400 páginas. Os resultados da pesquisa permitiram a identificação e a seleção de três objetos discursivos (capitalismo empreendedor, ascensão econômica no livre mercado e herói global) vinculados ao tema "empreendedorismo". Em conjunto, os três objetos discursivos identificados permitem que se explorem algumas possíveis implicações nas relações de trabalho contemporâneas em relação: (1) ao discurso da mídia, que estabelece uma convergência entre os interesses das organizações e os interesses dos indivíduos; (2) às novas configurações da esfera do trabalho em um modelo de capitalismo empreendedor; (3) à busca do sucesso profissional como organizador do comportamento humano no mundo do trabalho.
\end{abstract}

Palavras-chave: Empreendedorismo. Capitalismo empreendedor. Análise de discurso. Análise crítica de discurso. Revistas de negócios.

\begin{abstract}
Using the perspective of Norman Fairclough's (2001) social theory of discourse, this paper aims at identifying and discussing possible implications for contemporary labor relations due to the creation and diffusion of the concept of "entrepreneurship" by the business magazines. The assumption guiding this study is that the discourse used bonds uncritically and without any kind of question - the theme "entrepreneurship" to growth, development, and enrichment of the organizations and the individuals who work for them, choosing and naturalizing market capitalism as the only possible socioeconomic model of development. To fulfill the proposed aim, this study is based on the critical discourse analysis (CDA) and focuses on material published in the Brazilian business magazines Você S/A Exame, Carta Capital,

\footnotetext{
${ }^{1}$ Professora Assistente do IAG/PUC Rio; Doutorado em Administração (EBAPE/FGV). Endereço: Rua Marquês de São Vicente, 225 Prédio IAG, Gávea, CEP 22451-900, Rio de Janeiro-RJ, Brasil. E-mail: alessandra.costa@iag.puc-rio.br 22250-900, Rio de Janeiro-RJ, Brasil. E-mail: denise.fb@globo.com e denise.barros@fgv.br

${ }^{3}$ Professor Titular EBAPE/FGV; Doutorado em Administração (EAESP/FGV). Endereço: Praia de Botafogo, 190/4º andar, Botafogo, CEP 22250-900, Rio de Janeiro-RJ, Brasil. E-mail: pemiliom@fgv.br
}

2 Professora da EBAPE/FGV; Doutorado em Administração (EBAPE/FGV). Endereço: Praia de Botafogo, 190/4º andar, Botafogo, CEP
\end{abstract}


and HSM Management, within the period from March 2004 to April 2009, totaling 112 reports and 400 pages. The results of the survey enabled the identification and selection of three discursive objects (entrepreneurial capitalism, upward economic mobility in the free market, and global hero) linked to the theme "entrepreneurship". Together, the three discursive objects identified allow us to explore some possible implications in contemporary labor relationships regarding: 1) the media discourse, which establishes a convergence between the interests of organizations and those of individuals; 2) the new configurations in the labor sphere in a model of entrepreneurial capitalism; and 3) the quest for professional success as an organizer of human behavior in the labor world.

Keywords: Entrepreneurship. Entrepreneurial capitalism. Discourse analysis. Critical discourse analysis. Business magazines.

\section{Introdução}

O tema "empreendedorismo" e seus desdobramentos vêm sendo valorizados como a principal base do crescimento econômico e da geração de emprego e renda na atualidade (BARROS e PASSOS, 2000; CHANLAT, 1995). Como argumentam Tonelli, Brito e Zambalde (2011), a temática está em plena ascensão. Considerado veículo ideal para inovar, aumentar a produtividade e melhorar modelos de negócios, alguns autores arriscam-se a afirmar que estamos vivendo a era do empreendedorismo (DORNELAS, 2008) ou o início de um capitalismo empreendedor (SCHRAMM e LITAN, 2008), uma vez que são os empreendedores que estão "[...] eliminando barreiras comerciais, e culturais, encurtando distâncias, globalizando e renovando os conceitos econômicos, criando novas relações de trabalho e novos empregos, quebrando paradigmas e gerando riqueza para a sociedade" (DORNELAS, 2008, p. 6).

No caso do Brasil, tal movimento adquire maior intensidade nos anos 1990. Por parte do governo federal, foram criados vários programas específicos voltados para o público empreendedor, como é o caso do programa Brasil Empreendedor, que vigorou de 1999 a 2002 e foi dirigido "[...] à capacitação de mais de seis milhões de empreendedores em todo o país, destinando recursos financeiros [...] totalizando um investimento de oito bilhões" (DORNELAS, 2008, p. 11). Em ação conjunta com o governo, cabe chamar a atenção para o papel do Serviço Brasileiro de Apoio às Micro e Pequenas Empresas (Sebrae) no fomento ao empreendedorismo. ${ }^{4}$ Além de promover o Desafio Sebrae (competição acadêmica cuja tarefa é administrar uma empresa virtual), o Empretec (programa de capacitação empresarial) e o Programa Jovem Empreendedor (programa de capacitação de jovens empreendedores na faixa etária entre 16 e 24 anos em parceria com o Ministério do Trabalho e do Emprego e agentes financeiros), a instituição também concede prêmios para as melhores práticas empreendedoras.

No que diz respeito às entidades de classe, a valorização do empreendedorismo ocorre por meio da criação de diversos cursos e programas de abrangência nacional. Como exemplo pode-se destacar o Programa de Ensino Universitário de Empreendedorismo da Confederação Nacional das Indústrias (CNI). Ao mesmo tempo, a CNI instituiu em 2008, como órgão consultivo, o Conselho Temático de Educação (Coed), cujos objetivos são: (a) promover a formação de qualidade para capacitar trabalhadores em face dos desafios do mercado; (b) identificar e apoiar a difusão de boas práticas educacionais; e (c) recomendar ações que fortaleçam a educação e o desenvolvimento do empreendedorismo (CONFEDERAÇÃO NACIONAL DA INDÚSTRIA, 2009).

${ }^{4}$ Entidade privada e de interesse público, foi criada em 1972 com foco no "[...] desenvolvimento do Brasil através da geração de emprego e renda pela via do empreendedorismo [...] e na aceleração do processo de formalização da economia por meio de parcerias com os setores público e privado, programas de capacitação, acesso ao crédito e à inovação, estímulo ao associativismo, feiras e rodadas de negócios" (SEBRAE, 2010). 
Outro exemplo de ações e práticas vinculadas à promoção do empreendedorismo é a criação, em 2004, do Conselho Empresarial de Jovens Empresários pelo Instituto Euvaldo Lodi da Federação das Indústrias do Estado do Rio de Janeiro (Firjan). O Conselho tem por objetivo incentivar o empreendedorismo e o surgimento de novas lideranças no meio empresarial e é composto por jovens dirigentes de empresas de diversos segmentos da indústria do Rio de Janeiro "[...] para discutir e formular ações sobre assuntos que vão desde o dia-a-dia do executivo, a relação universidade x empresa, inovação, até o papel social das empresas e a imagem que a sociedade tem do empreendedor" (FEDERAÇÃO DAS INDÚSTRIAS DO ESTADO DO RIO DE JANEIRO, 2009). Ainda dentro do Sistema Firjan, pode-se destacar o Programa Pequenos Empreendedores, do Serviço Social da Indústria (Sesi), que oferece cursos de curta duração abertos às comunidades locais, visando à geração imediata de renda com baixo custo de investimento inicial. Também em 2004 foi criado o Comitê Jovens Empreendedores (CJE) da Federação das Indústrias do Estado de São Paulo (Fiesp), composto por um grupo de mais de 600 jovens com o objetivo de construir uma nova identidade empresarial por meio do fortalecimento do empreendedorismo paulista.

No âmbito das principais centrais sindicais brasileiras - a Central Única dos Trabalhadores (CUT), a Central Geral dos Trabalhadores (CGT) e a Força Sindical - esta temática adquire relevância, em especial quanto a questões de formação profissional e inserção mais qualificada no mercado de trabalho. A participação do movimento sindical nos debates sobre os rumos que a educação básica, o ensino e a formação profissional devem tomar adquire contornos estratégicos e seus encaminhamentos podem ser identificados no documento elaborado em 1996, intitulado “A Carta do Rio: Educação e Emprego no Brasil do Próximo Milênio". Junto com diretrizes como a promoção da distribuição de renda, a escolarização como exercício de cidadania, a justiça social, desenvolvimento sustentável e a igualdade de acesso, o tema empreendedorismo é atrelado à educação profissional, devendo esta "[...] pretender o fomento do trabalho, entendido como a atividade humana produtiva no sentido amplo, como elemento pilar para a construção da cidadania e para o desenvolvimento da capacidade empreendedora" (CENTRAL ÚNICA DOS TRABALHADORES, CENTRAL GERAL DOS TRABALHADORES e FORÇA SINDICAL, 2010).

No que se refere à área educacional, o tema empreendedorismo incorpora-se às grades curriculares das Instituições de Educação Superior mediante as Diretrizes Curriculares Nacionais do Curso de Graduação em Administração, que sugerem um perfil de administrador que desenvolva, entre outros pontos, uma capacidade empreendedora e crítica (SARAIVA, 2007). Ao mesmo tempo, além das disciplinas relacionadas ao tema e que vieram a integrar os currículos, as instituições de ensino superior passam a incentivar a abertura de empresas juniores (EJ) como forma de promover uma maior integração entre as práticas acadêmicas e as práticas de mercado (RIBEIRO e SACRAMENTO, 2009). Essa aproximação torna-se tão significativa que alguns pesquisadores identificam e valorizam a existência de um chamado empreendedorismo acadêmico (IPIRANGA, FREITAS e PAIVA, 2010).

No caso das empresas, as discussões mais recentes giram em torno do fenômeno do empreendedorismo como viabilizador da inserção estratégica em um mercado global imprevisível, turbulento e competitivo (LUMPKIN e DESS, 1996; MINTZBERG, 1973). Assim, destaca-se a importância de se desenvolverem nas organizações e nos indivíduos que nelas trabalham - uma atitude e uma cultura empreendedoras (BALBI et al., 2009; SOUZA e DEPIERI, 2007) que contemplariam: (a) o fomento da inovação; (b) a busca e identificação de oportunidades; (c) o trabalho criativo; (d) a visão integrada tanto da organização do trabalho quanto dos processos; (d) a eliminação de barreiras internas de comunicação; e (e) a incorporação dos riscos nos processos de tomada de decisão.

Concomitantemente o tema tem despertado o interesse da mídia de negócios: quem é, afinal de contas, o empreendedor e como esse fenômeno pode ajudar a potencializar carreiras, estratégias empresariais e o desenvolvimento socioeconômico dos países? Nos últimos anos, este segmento cresceu e livros e revistas afins podem, nos dias de hoje, ser identificados como entre os mais vendidos e mais populares. Um ponto importante a se ressaltar refere-se à localização dos títulos relacionados com o tema em livrarias, bancas de jornal e aeroportos. Posicionam-se em estantes "[...] cada vez mais semelhantes - no que tange a título, 
diagramação, cores das capas e, obviamente, conteúdo - às estantes com livros esotéricos e de auto-ajuda" (CARVALHO, CARVALHO e BEZERRA, 2010, p. 1). Ainda segundo estes autores, não é difícil, também, encontrar estas três categorias misturadas em uma única seção. Tal semelhança explicita dois pontos: (a) por um lado, a mercantilização das ideias e práticas de gestão baseadas em modismos gerenciais; (b) por outro, a existência de um leitor menos crítico e reflexivo com relação às novas informações que absorve em suas leituras. Assim, esse processo adquire contornos ideológicos quando inserido em contexto de valorização de receitas prontas oferecidas pelo mercado, o que contribui para a homogeneização de conceitos e práticas e a propagação de modelos de profissionais idealizados, apresentando o tipo ideal do empreendedor como o do herói emblemático que ousa desbravar novos caminhos, incorpora o risco em suas ações, quebra regras e reconhece oportunidades onde ninguém mais as consegue perceber.

Desse modo, esta pesquisa tem sua atenção direcionada para algumas possíveis implicações da criação e disseminação do conceito de empreendedorismo pela mídia de negócio nas relações de trabalho contemporâneas. De forma complementar, a suposição que norteia este estudo é a de que o discurso utilizado vincula, de forma acrítica e sem questionamentos, o tema empreendedorismo com o crescimento, desenvolvimento e enriquecimento das organizações e dos indivíduos nas organizações, elegendo e naturalizando o capitalismo de mercado como único modelo possível de desenvolvimento socioeconômico.

Dentro da problemática definida, três inquietações subjacentes passam a direcionar e a articular os caminhos deste trabalho. Uma primeira questão diz respeito à importância do discurso. Neste trabalho assume-se que: (a) os discursos não apenas refletem entidades e relações sociais como também as constroem; (b) o discurso não é aquilo que traduz somente as lutas ou os sistemas de dominação, mas aquilo pelo que se luta (FOUCAULT, 2007); (c) nenhuma linguagem é neutra, bem como determinados usos da linguagem e de outras formas simbólicas são ideológicos, ou seja, estabelecem e mantêm, em circunstâncias específicas, relações de poder e dominação; (d) tentativas de definir a direção da mudança incluem, cada vez mais, tentativas de mudar as práticas de linguagem (FAIRCLOUGH, 2001).

Uma segunda questão relaciona-se com o papel designado ao empreendedor e ao empreendedorismo na contemporaneidade. Segundo Aktouf (2002), essa dinâmica - com novas bases e critérios de gestão direciona as organizações a buscarem novas lógicas de ação e profissionais que criem valores, catalisem ideais em torno dos quais os demais indivíduos devem mobilizar-se objetivando a produtividade e um desempenho sustentável. Neste processo, o capitalismo de mercado (com suas desigualdades e idiossincrasias inerentes ao seu modelo de desenvolvimento) não é questionado, o que ocorre é apenas uma alteração discursiva em sua denominação: a sociedade empreendedora é regida pelas regras de um capitalismo empreendedor (SCHRAMM e LITAN, 2008).

Uma terceira questão diz respeito às relações de poder e de dominação presentes no atual mundo do trabalho. Qual modelo de trabalhador o conceito de empreendedorismo privilegia? Tal questionamento apresenta-se realmente relevante quando inserido em um contexto internacional de fluxo global de riquezas, imagem e poder? Cabe indagar-se a quem interessa a disseminação de um modelo conceitual que privilegia o empreendedor de "[...] conteúdo capitalista, ocidental, branco, masculino, heterossexual e euro-norteamericano - tido como certo e como padrão a ser copiado por todos os demais" (SARAIVA, 2007, p. 6).

Este trabalho está organizado em cinco seções. Após esta introdução, no referencial teórico, abordam-se diferentes interpretações sobre os conceitos de empreendedor, empreendedorismo e a sua relação com a mídia de negócios. Em seguida, explicitam-se os procedimentos metodológicos da pesquisa empírica. Na quarta seção são apresentados e discutidos os resultados da pesquisa por meio da identificação e a seleção de um conjunto de objetos discursivos vinculados ao tema do empreendedorismo presentes nas matérias das revistas analisadas. Na quinta - e última seção - apresentam-se as considerações finais e sugestões para pesquisas futuras. 


\section{Referencial Teórico: Empreendedorismo}

Ao longo da história, inúmeras foram as tentativas de definição de empreendedorismo, do seu principal agente - o empreendedor - e de seu papel na sociedade. De forma mais geral, alguns autores defendem a ideia de que não existe consenso em relação ao tema do empreendedorismo (BOAVA e MACEDO, 2009; COLBARI, 2007) e que dar início a uma pesquisa sobre o assunto assemelha-se a entrar em "um bazar" onde "[...] encontra-se de tudo, para todos" (FILION, 1999, p. 8), No entanto, de forma bastante genérica, pode-se identificar duas abordagens com focos distintos: (a) behaviorista ou comportamental; e (b) econômica.

O foco da abordagem behaviorista concentra-se nas tentativas de definição dos perfis das personalidades do empreendedor, em seu comportamento e nos aspectos relacionados com as suas origens e contextos de emergência (BORGES e CASADO, 2009; KETS de VRIES, 1977). De forma complementar, as indagações que norteiam tais pesquisas seriam: todo indivíduo nasce empreendedor? O potencial empreendedor pode ser estimulado e desenvolvido no decorrer da vida de um indivíduo? O empreendedorismo é passível de ser ensinado? (NASSIF et. al., 2008; SOUZA e SOUZA, 2008).

De acordo com Filion (1999), dos anos 1970 aos anos 1980 foram os behavioristas que dominaram a área do empreendedorismo, em grande parte pelos trabalhos de David McClelland $(1961,1972)$ e pelos avanços nas ciências do comportamento. Portanto adquire relevância a identificação das características e habilidades mais relevantes dos empreendedores (ZAMPIER e TAKAHASHI, 2011). De acordo com os estudos inseridos nesta abordagem, apesar dos contextos e de circunstâncias de pesquisa diferentes, as características mais destacadas dos empreendedores são, na maior parte das vezes, as mesmas: (a) valores e cultura do empreendedorismo adquiridos por meio de um modelo empreendedor durante a juventude; (b) tenacidade e capacidade de tolerar ambiguidades e incertezas; (c) experiência em negócios; (d) diferenciação; (e) intuição; (f) envolvimento (os empreendedores são considerados trabalhadores incansáveis); (g) assumem correr riscos moderados; (h) sonhadores realistas (visionários); (i) imaginativos; (j) líderes; (k) buscam resultados efetivos; (l) trabalham em rede; (m) possuem seu próprio sistema de relações com os funcionários; (n) controlam o comportamento das pessoas ao seu redor; (o) desenvolvem um processo de aprendizagem por meio de seus próprios padrões (CASTANHAR, 2007).

Entretanto, o foco da abordagem econômica do empreendedorismo concentra-se nas relações entre o tema e as ideias de inovação, risco calculado e desenvolvimento. A ascensão socioeconômica dos empreendedores é entendida como tendo início entre o fim do século XVIII e início do século XIX, inserida em um contexto econômico refletido pelas forças livres do mercado e da concorrência.

É neste contexto que, na segunda metade do século XVIII, Richard Cantillon (2002) faz um esforço no sentido de tentar identificar quem é esse indivíduo empreendedor, vinculando a sua representação não à sua função na sociedade, mas ao seu posicionamento em relação ao risco resultante das oscilações de oferta e demanda. Este indivíduo, o empresário, poderia ser tanto o comerciante, o artesão/produtor de manufatura ou o colono agricultor. Segundo Filion (1999, p. 4), em um contexto de revolução industrial, o interesse de Cantillon pelos empreendedores não era um fenômeno isolado e sim harmônico às ideias dos pensadores liberais da época que "[...] exigiam [...] liberdade plena para que cada um pudesse tirar o melhor proveito dos frutos do seu trabalho".

Outro importante economista liberal que, de alguma forma, ressaltou uma função especial para o empreendedor na sociedade foi Jean Baptiste Say (SCHUMPETER, 1968, p. 113). Para este, o empreendedor é o empresário e se posiciona no centro do processo econômico de forma a equilibrá-lo, assumindo o papel de intermediário entre as classes de produtores e entre os produtores e o consumidor. Desta maneira, o empreendedor passa a ser de fundamental importância no processo de desenvolvimento econômico, dada a sua capacidade de combinação e transferência de recursos de setores de baixa para os de alta produtividade (GOMES, 2005). Cabe ressaltar que a imagem do empreendedor como empresário e, ou 
como capitalista provedor do desenvolvimento econômico é uma representação recorrente na época (ver MARX e ENGELS, 1980).

No entanto, a definição resgatada e mais utilizada na atualidade acerca do empreendedorismo é a extraída do economista Joseph Schumpeter. Em seus escritos dos anos de 1910 e 1920, o empreendedor é compreendido, sobretudo, como um inovador que impulsiona o desenvolvimento econômico por meio da reforma ou revolução do padrão de produção. Schumpeter (2001) explica o processo de desenvolvimento econômico (e seus ciclos) como decorrência do surgimento de novas combinações e novos usos de recursos, quais sejam: (a) introdução de um novo bem ou de um bem já existente com nova característica; (b) introdução de um novo método de produção; (c) abertura de um novo mercado; (d) descoberta de novas fontes de suprimento; (e) desenvolvimento de novas formas de organização.

Estas inovações são apresentadas como potencializadoras de desequilíbrios (ou perturbações) que movimentam as economias e as sociedades em direção ao desenvolvimento. E o empreendedor é o agente que inicia tais mudanças, alterando o sistema em equilíbrio ao identificar novas oportunidades. O destaque atribuído às questões do caráter inerentemente inovador do empreendedor permanece presente em definições mais atuais que privilegiam novas oportunidades de investimento, de produto ou de negócios (BYGRAVE e HOFER, 1991; KRUGER e BRAZEAL, 1994) ou a criação de novas empresas (GARTNER, 1989).

As duas abordagens, no entanto, convergem para um mesmo ponto, que ressalta a emergência de uma sociedade fundamentada em um mercado livre capaz de produzir cada vez mais riquezas uma vez que seu principal agente são os empreendedores, isto é, os indivíduos capazes de criar e aproveitar oportunidades, melhorar processos e inventar negócios. De acordo com López-Ruiz (2007), tais procedimentos são coerentes com a reformulação neoliberal da economia política contemporânea, em que o espírito do capitalismo produz um repertório de explicação da realidade que toma a figura do executivo como matriz de uma conduta a ser disseminada pela sociedade inteira, fundada no investimento constante e exclusivo da vontade na produção da riqueza abstrata (BOLTANSKI e CHIAPELLO, 2009). Esta matriz prolonga e intensifica a obrigação do homem moderno de dedicar sua vida ao ganho, reduzindo os atributos dos indivíduos à dimensão do interesse e incorporando a lógica do capital "[...] como se ela fosse, mais do que a razão de sua existência, o fundamento último da própria vida humana em sociedade" (SANTOS, 2007, p.21).

É neste sentido que, nos dias de hoje, a busca pelo ganho é mais do que uma obrigação, e o indivíduo passa a ser qualificado como o sujeito econômico capitalista por excelência (LEMOS, 2005). Inseridos nesta lógica, os empreendedores são concebidos como indivíduos que impulsionam a máquina capitalista ao prover novos bens de consumo e inovadores métodos de produção e transporte, com a função social de identificar oportunidades e convertê-las em valores econômicos. Desta forma, o empreendedorismo apresenta-se como fundamental para o desenvolvimento econômico, potencializando lucros por meio de uma "visão" ou um "espírito" muitas vezes mais pessoal do que coletivo.

\section{Empreendedorismo e a mídia de negócios}

A mídia de negócios pode ser entendida como pertencente a um conjunto maior denominado por Micklethwait e Wooldridge (1998) de "indústria da teoria da administração" ou "indústria do management". Também inseridos neste conjunto ainda coexistem e compartilham pressupostos: (1) as empresas de consultoria em administração; (2) as faculdades de Administração; (3) os gurus (ECCEL, GRISCI e TONON, 2007). Segundo Fonseca (2003), a indústria do management contribui para a homogeneização dos conceitos e práticas administrativas, apresentando-se como um importante veículo na disseminação de ideologias na sociedade em virtude da abrangência de seu poder de comunicação e pela sua capacidade de publicizar ideias. 
É importante chamar a atenção para o fato de que a indústria do management vincula-se à mídia de massa em geral, articulando e difundindo "[...] uma visão de mundo particular, edificando idéias, comportamentos, projetos econômicos e políticos [...]" (DIAS et al., 2007). Assim, alimenta um imaginário social específico (WOOD JR. e PAULA, 2006) e se efetiva por meio de um processo de: (a) promoção de valores associados ao sucesso profissional; (b) indução pelo poder da influência e do prestígio de agendas específicas junto ao público executivo; (c) divulgação sistemática de novidades gerenciais; (d) legitimação das novidades gerenciais (MICKLETHWAIT e WOOLDRIDGE, 1998; WOOD JR. e PAULA, 2001).

É neste sentido que o ideário do empreendedorismo, por meio da mídia de negócios, vem adquirindo a força de dogma, uma vez que a sua validade e atemporalidade não são questionadas. Ao mesmo tempo, ao ser universalizado, adquire contornos de ideologia, inibindo reflexões mais críticas sobre o significado de sua hegemonia histórica e consequências na vida social, organizacional e pessoal (WOOD JR. e PAULA. 2001). Pode-se assumir que, no caso do empreendedorismo, a mídia de negócios constrói e dissemina os seguintes pressupostos: (a) a crença da sociedade no mercado livre; (b) a visão do indivíduo como autoempreendedor; (c) o culto da excelência como forma de aperfeiçoamento individual e coletivo; (d) o culto de símbolos e figuras emblemáticas; (e) a crença em tecnologias gerenciais que permitem racionalizar as atividades grupais organizadas (WOOD JR. e PAULA, 2001).

Estes pressupostos são divulgados e corroborados por um movimento convergente de interesses - de editores, relações públicas das organizações e anunciantes - que expressam o seu papel articulador e difusor de uma visão de mundo particular. De forma simultânea, os temas gerenciais, por meio de reportagens, entrevistas, depoimentos e propaganda, respondem às ansiedades e às inseguranças de seus respectivos leitores por intermédio de receitas prontas, fórmulas gerenciais mágicas e modismos, tais como: "Como o novo executivo salvou a empresa", "A última palavra em software empresarial", "Como a empresa inovadora conquistou o mercado" (WOOD JR., 2001, p. 105). E, como argumentam Rodrigues, Morin e Strehlau (2009), os veículos de comunicação de massa constituem uma fonte importante para a construção da identidade do indivíduo e de suas interações sociais; e as histórias de sucesso, as biografias de celebridades, as receitas para melhorar o desempenho apresentam-se fundamentais para gerar uma ilusória, e pretendida, sensação de conforto.

\section{Procedimentos Metodológicos}

Para construção do corpo de dados, foram coletadas as matérias publicadas nas revistas Você S/A, Exame, CartaCapital e HSM Management entre março de 2004 e abril de 2009 - recorreu-se, assim, deliberadamente à literatura da mídia de negócios. O critério que orientou a seleção das matérias nas revistas foi a identificação dos termos "empreendedor" ou "empreendedorismo" no título ou subtítulo da coluna ou matéria, em um total de 112 reportagens e 400 páginas sobre o tema no período. Os dados foram analisados segundo análise do discurso de forma a embasar e conduzir os protocolos metodológicos requeridos.

Assume-se neste trabalho que a análise do discurso é o estudo sistemático de um conjunto de textos que tem por objetivo desvendar a forma como os discursos adquirem significado por meio de atividades que incluem a produção, a distribuição e o consumo destes mesmos textos. Mais do que interpretar a realidade social como ela existe, a análise do discurso busca compreender como a realidade social é produzida (HARDY, 2001). Como desdobramento, por meio da análise de um conjunto de discursos, podem-se encontrar as motivações de um dado grupo, o que desvendaria os interesses, a ideologia e as relações de poder existentes em um contexto específico. A ideia é desmontar os elementos subjacentes aos discursos para identificar a voz do autor e seu posicionamento, seja este autor um indivíduo, uma empresa ou um governo (BOJE, 1995). Assume-se, também, que a análise de discurso é um método interdisciplinar (ALVESSON e KARREMAN, 2000) e multidisciplinar (GRANT, KEENOY e OSWICK, 2001) utilizado para a investigação dos mais 
diversos fenômenos sociais e contextuais e que ganha espaço cada vez mais abrangente na área de Estudos Organizacionais (FARIA e MENEGHETTI, 2001; HARDY, 2001).

Neste trabalho, os dados foram coletados por meio dos seguintes procedimentos: (1) seleção das matérias; (2) leitura crítica; e (3) identificação dos objetos discursivos mais relevantes. Por último, a perspectiva defendida aqui comporta a ideia de que todo conhecimento empírico acerca das organizações é socialmente construído (ALVESSON e DEETZ, 1998; MISOCZKY, 2003), cabendo ao pesquisador encontrar os significados associados por estas construções sociais à ação organizacional. Toda palavra traz consigo certo número de conotações obscuras, passíveis de investigações que revelem intenções ocultas, pressuposições veladas e ambiguidades implícitas. Nos discursos, tais estruturas linguísticas e metalinguísticas estão naturalmente presentes, e sua captura e seu estudo sistemático possuem relevância científica (ALVESSON e KARREMAN, 2000; STEFFY e GRIMES, 1986).

A abordagem aqui adotada foi a critical discourse analysis (CDA) e, de forma mais específica, a perspectiva da teoria social do discurso de Norman Fairclough (2001). Esta pressupõe a utilização de um esquema tridimensional (FAIRCLOUGH, 2001, GRANT, KEENOY e OSWICK, 2001; HARDY, 2001) de análise no qual o evento discursivo (qualquer exemplo de discurso) é analisado tendo como base a ideia de que este é simultaneamente (a) um pedaço de texto; (b) uma instância de prática discursiva; e (c) uma instância de prática social. Cabe ressaltar que a CDA é uma abordagem de certa forma já bem estabelecida de estudo do mundo social e uma das mais populares metodologias utilizadas para a análise de textos e de linguagem tanto em Administração quanto em Estudos Organizacionais (LEITCH e PALMER, 2010).

\section{Representação dos Resultados}

Os resultados da pesquisa permitiram a identificação e a seleção de um conjunto de objetos discursivos vinculados ao tema do empreendedorismo, quais sejam: (a) capitalismo empreendedor; (b) ascensão econômica no livre mercado; e (c) herói global.

\section{Objeto discursivo: capitalismo empreendedor}

Um primeiro objeto discursivo identificado foi capitalismo empreendedor. Nos textos analisados, os termos muitas vezes se sobrepõem: sociedade empreendedora, economia empreendedora, ecologia empreendedora, forças propulsoras do empreendedorismo e era do empreendedorismo. No entanto, uma essência comum permanece: a intrínseca, naturalizada e inevitável relação entre empreendedorismo, capitalismo e desenvolvimento socioeconômico.

Toda geração precisa de uma nova revolução, escreveu Thomas Jefferson. A revolução atual é a do empreendedorismo. [...] Usa mais a inteligência, em mais países e de maneiras mais criativas, para aumentar a produtividade e resolver problemas sociais. (A SOCIEDADE ..., 2009, p.61)

Identifica-se nos textos a ideia de que a produtividade capitalista baseia-se em uma lógica produtivista racional, que tem por objetivo o crescimento econômico.

Victor Hugo certa vez observou: "você pode resistir a um exército invasor, mas não pode resistir a uma idéia que amadureceu”. O empreendedorismo hoje é essa ideia. (UMA IDEIA..., 2009, p.50). 
Empreendedorismo capitalista. [...] Esse capitalismo não é tão desestabilizador como muitos de seus apoiadores imaginam. Ele produz um bolo maior de riquezas e permite a mais pessoas exercitarem os seus talentos criativos. (A SOCIEDADE... 2009, p.61).

Inserido nesta lógica, a busca pelo lucro não é algo negativo, pelo contrário, lucro é algo inerente ao crescimento e desenvolvimento econômico, seja individual, regional, nacional ou internacional:

Recentemente surgiu o chamado setor '2 e meio', para diferenciá-lo do terceiro setor, que são as ONGs sem fins lucrativos. No caso do '2 e meio', busca-se criar soluções comunitárias sem abrir mão do lucro. (EMPREENDEDORISMO no... 2009, p.54).

A positividade atribuída ao lucro é identificada em várias matérias e o discurso é bastante homogêneo, sendo considerado a base principal das relações em sociedade. Assim, os benefícios e resultados do crescimento econômico manifestam-se de diferentes formas nas reportagens, como, por exemplo, por meio da geração de riquezas, de emprego e de renda:

O potencial de renovação da classe empresarial é fundamental para a geração de novos empregos, a melhoria da distribuição de renda, e, em última análise, para o crescimento de toda a nação. (DO ZERO..., 2006, p.24).

Por meio de inovação e do desenvolvimento tecnológico:

Em mercados cada dia mais voláteis e competitivos, a inovação tornou-se a fonte para acelerar o crescimento das vendas, valorizar as ações e estabelecer certas vantagens competitivas [...] (O MELHOR..., 2006, p.2).

O espírito empreendedor na economia do mundo todo aumenta, e muito desse espírito é, sem dúvida, impulsionado pelo desenvolvimento de novas tecnologias que fazem com que seja cada vez mais barato e mais fácil abrir uma empresa própria. (NADA..., 2007, p.172).

Ou, ao mesmo tempo, por meio do incentivo à criatividade como forma de ultrapassar barreiras e cenários de grande risco:

Para superar esses fatores negativos [escassez de crédito, excesso de burocracia e de impostos e capacitação insuficiente] os empreendedores precisam abusar de uma palavrinha quase mágica: criatividade. (QUINTETO..., 2006, p.42).

Alavanca capaz de mover o mundo, o empreendedorismo floresce nas sociedades que valorizam a educação e a criatividade, que investem em pesquisas e que se mostram abertas às iniciativas de inovação. (A ALAVANCA..., 2007, p.66).

Como resultado, melhora-se a qualidade de vida da população tornando o mundo um lugar melhor e mais justo de se viver:

Complexo e multifacetado na essência, o empreendedorismo produz mudanças individuais e coletivas que, graças a seu caráter interdependente, modificam o mundo. (A ALAVANCA..., 2007, p.61). 
[...] É fruto de um processo que representou um renascimento econômico para a cidade. [...] A reinvenção de Cianorte é uma mostra clara de como o empreendedorismo pode transformar a vida de uma comunidade. (A CIDADE..., 2006, p.54).

A ascensão do empreendedor não diz respeito apenas à economia. [...] Ela sinaliza o nascimento de uma sociedade empreendedora. (A SOCIEDADE..., 2009, p.61).

Cabe ressaltar, também, a identificação nos discursos analisados da eleição dos Estados Unidos da América como o representante, por excelência, do capitalismo empreendedor, tendo-se por sugestão que o seu modelo seja replicado pelos demais países:

O país [EUA] foi fundado e colonizado por aventureiros dispostos a sacrificar velhas certezas por novas oportunidades. (OS ESTADOS UNIDOS..., 2009, p.53).

Os EUA foram o primeiro país, no final dos anos 1970, a abandonar o capitalismo administrado pela variedade empreendedora. (OS ESTADOS UNIDOS..., 2009, p.53).

[...] Os EUA desempenham um papel vital na disseminação da cultura do empreendedorismo. [...] Pessoas em todo o mundo admiram a habilidade de o país produzir empreendedores transformadores, como Bill Gates, universidades criadoras de riqueza, como Harvard e Stanford, e agrupamentos vitoriosos, como o Vale do Silício. (OS ESTADOS UNIDOS..., 2009, p.54).

Em consonância com esta exemplaridade, quanto mais próximos os países se encontrarem do modelo capitalista empreendedor liberal norte-americano, mais frutos poderão colher do processo:

Nas últimas duas décadas, a Índia saiu de uma pesada estrutura burocrática [...] e transformou-se na terra dos empreendedores libertos. [...] O espírito do país mudou muito desde que o governo começou a abrir a economia em 1991. O fatalismo foi substituído pelo otimismo do poder fazer. (QUANTO MAIS..., 2009, p.55).

A China e a Índia têm um longo caminho a percorrer. [...] Quanto à China [...] o capitalismo está distorcido pela influência dos políticos. [...] [Mas] Os capitalistas vermelhos da China, apesar de contidos pelo partido, estão por seu lado forçando-o a mudar. (QUANTO MAIS..., 2009, p.56).

Cabe ressaltar que problemas que possam advir desse papel vital norte-americano não são abordados ou discutidos nos discursos analisados, configurando-se como silêncios ou omissões discursivas. Um silêncio, por exemplo, relaciona-se, com a ideia de que empreendedores como Bill Gates devam ser modelos exemplares de sucesso. Não é, no entanto, destacada nas reportagens a informação de que tanto a sua fortuna quanto o seu sucesso são baseados em um monopólio mundial.

Assim, em um cenário contemporâneo de crescente concentração de riquezas nas mãos de poucas organizações multinacionais e transnacionais, Aktouf $(2004$, p. 49) chama a atenção para o fato de que "[...] pode-se facilmente provar que, como o dinheiro não é senão mercadoria, serviços, logo, trabalho 'cristalizado', e que sua acumulação não é mais que transferência entre vasos comunicantes, 100 Bill Gates representariam a miséria para a quase totalidade do planeta, e no fim, a miséria para eles mesmos". Outro silêncio diz respeito às implicações de ordem política e econômica internacional do papel atribuído aos EUA como propagador do empreendedorismo no mundo. A legitimidade deste papel precisa ser discutida para que não ocorra apenas uma releitura contemporânea de algo como o Destino Manifesto -crença de que o povo 
norte-americano foi eleito por Deus para comandar o mundo e base ideológica do seu expansionismo e intervencionismo a partir da segunda metade do século XIX -, agora adaptado ao tema empreendedorismo.

\section{Objeto discursivo: ascensão econômica no livre mercado}

Um segundo objeto discursivo identificado vincula-se à ideia de ascensão socioeconômica em um contexto refletido pelas livres forças do mercado e da concorrência. Argumenta-se que, na atualidade, para que uma sociedade possa potencializar todos os benefícios provenientes de um mercado livre, necessita de um ambiente propício à emergência do espírito empreendedor:

As mudanças formidáveis ocorridas na vida desses empresários só são possíveis num ambiente de negócios que minimamente reconhece a inovação, o senso de oportunidade e premia o risco. O surgimento de novos negócios - e a sobrevivência dos mais fortes - só é possível numa sociedade que abraçou o capitalismo. (O PAÍS..., 2007, p.46).

[...] O espírito empreendedor é um dos fatores essenciais para aumentar a riqueza de um país e melhorar as condições de vida de seus cidadãos. Sociedades em que os níveis de empreendedorismo vêm decaindo sofrem dramaticamente as conseqüências desse processo. (DO ZERO..., 2006, p.25).

Este discurso alinha-se com a argumentação de Boltanski e Chiapello (2009), Lemos (2005) e Lemos e Rodrigues (2008) de que o indivíduo, na contemporaneidade, passa a ser qualificado como o sujeito econômico capitalista por excelência e que precisa de um ambiente propício à emergência de seu espírito empreendedor. Desse modo, produtos e produtores deste contexto, os empreendedores são considerados aqueles que, mesmo diante das mais complexas dificuldades, rompem as barreiras e impulsionam a máquina capitalista ao prover novos bens de consumo e métodos inovadores de gestão e produção:

Há problemas graves e sérios que comprometem a saúde das companhias brasileiras. [...] Mas o que existe é uma estirpe de homens de negócios que, em algum momento de sua história, conseguem fazer com que a inovação supere as velhas dificuldades que todos conhecemos. (DO ZERO..., 2006, p.20).

Essa nova geração de empresários, no entanto, tem desafios muito diferentes do passado. $\mathrm{O}$ principal deles é que esses negócios nasceram sob o signo da competição global, na qual o protecionismo do governo - crucial para outras gerações - já não existe mais (DO ZERO..., 2006, p.26).

Desta forma, os discursos corroboram a ordem econômica mundial atual como natural e contra a qual nada se pode fazer, a não ser a ela aderir. Com relação a este ambiente, os textos omitem algumas discussões relevantes para uma leitura mais crítica do tema, tais como: seria a crescente concentração de poder e de riquezas realmente favorável à concorrência e à competitividade? $\mathrm{O}$ atual estágio do capitalismo não favorece a concentração do capital, as megafusões e os oligopólios - inimigos mortais do mercado e da concorrência? Como aceitar sem questionamentos que o mercado seja "[...] uma espécie de laboratório transparente, limpo e asséptico, onde os jogadores são todos honestos?” (AKTOUF, 2002, p.49). 


\section{Objeto discursivo: o herói global}

Um terceiro - e último - objeto discursivo refere-se à imagem do empreendedor como herói global. Um ponto importante em relação a este objeto discursivo diz respeito à argumentação de López-Ruiz (2007) de que o espírito empreendedor vincula-se a um novo espírito do capitalismo que produz um repertório de fórmulas generalizáveis - e, portanto, passíveis de serem replicadas. Assim, é indiferente para as matérias analisadas se a capacidade de agir proativamente e, ou a competitividade agressiva, por exemplo, referem-se às ações de um indivíduo empreendedor, de uma empresa empreendedora multinacional ou de um país empreendedor do terceiro mundo.

Nos textos analisados, o empreendedor é celebrado como herói, sua história de conquistas e sua trajetória de realizações são atribuídas a características capazes de promover resultados que expressam sucesso empresarial: ambição, autoconfiança, dinamismo e intuição.

Poucos empreendedores hoje chamam tanto a atenção do setor quanto ele. Ex-estrela do mercado de tecnologia, jovem, ambicioso e dono de uma autoconfiança que beira a pretensão, Agassi [Shai Agassi] fez carreira e fortuna com softwares, terreno que domina desde criança - ele programou seu primeiro computador aos 7 anos. (VISIONÁRIO..., 2008, p.49).

Como aponta Enriquez (1997, p. 1), a atualidade assiste a um retorno do indivíduo como mestre do seu destino, a uma "[...] transformação de toda pessoa em guerreiro, em esportista, em herói, indo à conquista de si mesmo, dos outros, dos mercados industriais e financeiros". Essa ideia pode ser identificada com clareza nos discursos, inclusive quando relacionada a um contexto de guerra:

[...] A principal qualificação de Israel para o empreendedorismo é o seu status como um estado judeu em prontidão para a guerra, cercado por um mar de hostilidade árabe. O exército de Israel não apenas trabalha duro para manter o país na vanguarda da tecnologia como também treina jovens [...] nas virtudes do trabalho em equipe e da improvisação. (TERRAS..., 2009, p.57).

A argumentação, no entanto, desdobra-se em outros pontos, mas agora já silenciados e sem reflexo no discurso da mídia de negócios. Ou seja, Enriquez (1997, p. 1) adverte que esta transformação é enganadora e a situação apresenta-se exatamente ao contrário, pois o individuo jamais "[...] esteve tão encerrado nas malhas das organizações (em particular, das empresas) e tão pouco livre em relação ao seu corpo, ao seu modo de pensar, à sua psique [...] e que tudo na sociedade [...] é construído para fazer o indivíduo crer na sua vocação de homem livre e criador".

De forma complementar ao sucesso em alcançar resultados, a busca incansável por novas oportunidades também faz parte das características deste herói global e o distingue dos demais indivíduos:

"Sua obsessão por trabalho chega a ser inconveniente", diz um amigo. "Até em eventos sociais ele prospecta novos negócios". (MEU NEGÓCIO..., 2008, p.55).

[...] [o empreendedor] tem um estilo de vida frenético. [...] quando distingue uma idéia promissora, ele funda uma empresa ou injeta fundos em um negócio existente [...]. uma vez que o negócio esteja rodando, vai embora em direção à próxima grande ideia. (EMPREENDEDOR..., 2007, p.107). 
As histórias sobre estes heróis são produzidas, reproduzidas e emuladas independente da nacionalidade do agente ou do país em questão, como é o caso de empreendedores chineses em seu país:

A enxurrada de exemplos de empreendedores e os anos de crescimento, porém, incendiaram a juventude chinesa, que passou a nutrir sonhos mais ambiciosos. Como os séculos mostram, no capitalismo ganha mais quem arrisca mais - e os chineses, agora, estão dispostos a tentar. (DESESPERADOS..., 2008, p.62).

[A sua lista de feitos] transformou Jack Ma numa espécie de super-herói do capitalismo vermelho. Professor de inglês até os anos 90, Ma subjugou gigantes americanos (o concorrente e-Bay e o sócio Yahoo!) e venceu no mundo da tecnologia. Ocidentalizado, moderno e destruidor de potências estrangeiras - uma metáfora poderosa demais [...] Não demorou, portanto, a se tornar um popstar. (BILIONÁRIO..., 2008, p.74).

De empreendedores no Japão:

Ito [Joichi Ito] é conhecido nos círculos de alta tecnologia por sua capacidade quase sobrenatural de identificar "a próxima grande coisa" bem antes de outras pessoas chegarem a ela [...] O primeiro servidor de Internet no Japão estava localizado no banheiro do seu apartamento em Tókio. (EMPREENDEDOR..., 2007, p.105).

E no Brasil:

Histórias de empresários que começaram do zero são a prova de que, apesar de todos os problemas, o Brasil é um dos poucos países no mundo que oferecem tantas condições de ascensão. (O PAÍS..., 2007, p.44).

As histórias devem servir de estímulo para outros empreendedores se manterem firmes no propósito de crescer, gerar emprego e oferecer bons serviços e produtos aos clientes. O que é bom para os próprios empresários e para o país. (QUINTETO..., 2006, p.42).

Mesmo quando as matérias abordam o tema do empreendedor corporativo (ou intraempreendedor), as habilidades e atitudes permanecem as mesmas, sendo apenas adaptadas ao novo contexto:

Mesmo quem não é empreendedor nato pode absorver as características de um para se desenvolver profissionalmente [dentro de organizações]. [...] O consultor americano Gifford Pinchot [...] diz que o profissional deveria ir ao trabalho todo dia preparado para ser demitido. (CABEÇA..., 2008, p.39).

Enfim, as histórias destes heróis generalizam modelos emblemáticos - construídos quase sempre baseados em experiências individuais, particulares, específicas e historicamente contextualizadas - que no entanto ao serem assumidos e replicados por indivíduos, empresas e governos, garantiriam o alcance do sucesso de todos.

\section{Considerações Finais}

Em conjunto, os três objetos discursivos identificados permitem explorar algumas possíveis implicações da criação e disseminação do conceito de empreendedorismo pela mídia de negócios nas relações de trabalho. 
Um primeiro ponto refere-se à existência nos textos de um discurso que estabelece uma convergência entre os interesses das organizações e os interesses dos indivíduos que trabalham em organizações. Esta convergência aparece de forma clara quando o tema é o desenvolvimento. De forma bastante genérica, podese definir desenvolvimento como um processo por meio do qual uma sociedade amplia as suas capacidades humanas, institucionais e técnicas para produzir os bens e os serviços necessários à conquista das melhorias sustentáveis em sua qualidade de vida usando os recursos de que dispõe (KORTEN, 1996). Poucos seriam os autores que discordariam da essência desta definição. Talvez alguns aspectos fossem mais ressaltados e outros menos valorizados.

No entanto, ao se afastar da definição generalista e se aproximar de definições mais específicas, as divergências tornam-se mais visíveis. E relevantes. O que é qualidade de vida? Qualidade de vida para as organizações é o mesmo que qualidade de vida para os indivíduos nas organizações? E mesmo entre os indivíduos, existe consenso? As respostas para estas indagações podem ser várias e as configurações do modelo de desenvolvimento socioeconômico a ser defendido e difundido vai depender de cada uma delas. No entanto, os discursos analisados acerca do empreendedorismo na mídia de negócios elegem apenas uma possível configuração: o empreendedorismo desempenha no mundo contemporâneo o papel de impulsionador do desenvolvimento e do crescimento econômico de todos baseado na lógica de produção capitalista de livre concorrência.

Como desdobramento, o modelo neoliberal proposto pelas nações dominantes parece ter alcançado um status de consenso, o que permite que sua transposição para outras sociedades seja vista como natural, inevitável, desejada e benéfica. Em vista de tal condição hegemônica, dificilmente são aceitas considerações críticas ao modelo, mesmo porque estas críticas não costumam oferecer as tão (aparentemente) esperadas alternativas ao sistema. Nesta lógica, não existe espaço para questionamentos mais substantivos, como: os interesses empresariais e os individuais são necessariamente convergentes? Segundo Korten (1996, p. 212), por exemplo, "[...] é impossível ter-se sociedades saudáveis, eqüitativas e democráticas quando o poder político e econômico está concentrado em algumas corporações gigantescas". Ou, como indaga Aktouf (2004, p. 6465): "Na corrida pela produção de bens materiais, no que se transformam o homem e a comunidade dos homens? Qual é, nesta corrida, a finalidade do econômico? [...] Por que produzir? Por que enriquecer? Quem se enriquece? Como se enriquece? Até que ponto? E em detrimento de quem?" Nada se diz "[...] a respeito das condições de trabalho, ou da precarização que acompanham a vida profissional da maior parte dos empreendedores, sendo apenas reforçados os estereótipos e mitos sobre as glórias do mundo dos negócios" (SARAIVA, 2007, p. 5). Talvez seja relevante a busca de outras respostas possíveis em abordagens alternativas que representem formas de sociedade mais justas, expandindo o domínio das experiências políticas, econômicas e sociais.

Um segundo ponto diz respeito a como a esfera do trabalho vai ser configurada em um capitalismo empreendedor. Ou seja, como conciliar capital e trabalho? Ou como converter o trabalhador em capitalista? O discurso da mídia de negócios apregoa de forma indiscriminada a possibilidade, e urgência, de todos os indivíduos serem empreendedores. Mesmo aquele indivíduo que não é um empreendedor nato pode desenvolver essa atitude e/ou habilidade. Subjacente a esse entendimento existe uma nova atitude em face da esfera produtiva, diferente da relação de trabalho tradicional.

O profissional contemporâneo passa a ser uma unidade econômica autônoma inserida em um contexto competitivo, sendo o "[...] eu empreendedor [...] um atributo fundamental do indivíduo empregável, que precisa autogerir a carreira, deve ser empresário de si próprio e ver a si mesmo como se fosse um negócio" (LEMOS e RODRIGUES, 2008, p. 2). Ainda que assuma a posição de empresário de si mesmo, existe uma real conciliação entre o capital e o trabalho? Mesmo Schumpeter - resgatado pelos acadêmicos como o grande definidor do que seria a figura do empreendedor - relativiza esta conciliação. A partir dos anos 1930, redefine suas ideias ao defender a tese de que a competição perfeita raramente havia existido na história e que não havia motivos para considerá-la um modelo de eficiência na promoção do crescimento econômico a longo prazo. Segundo este autor, "[...] o impulso fundamental que põe e mantém em funcionamento a 
máquina capitalista procede de novos bens de consumo, dos novos métodos de produção ou transporte, dos novos mercados e das novas formas de organização industrial criadas pela empresa capitalista" (SCHUMPETER, 1961, p. 105). Desta forma, seriam as grandes empresas, e não mais os indivíduos, os principais agentes promovedores dos processos de destruição criadora que impulsionam o capitalismo de mercado.

Um último ponto a ser destacado relaciona-se com a questão da busca do sucesso profissional. Esta busca pode ser compreendida como um poderoso organizador do comportamento humano no mundo do trabalho, uma vez que este estabelece uma série de referenciais e senso de direção (WOOD Jr. e PAULA, 2001) aos indivíduos. O discurso da mídia de negócios corrobora estes referenciais ao sugerir que, por meio do sucesso alcançado, os empreendedores são donos do seu destino e controlam as incertezas e imprevisibilidades da vida. Assim, em um contexto de incertezas e mudanças, os textos oferecem aos indivíduos soluções simples - por meio de receitas, guias e fórmulas - para problemas complexos: o sucesso passa a ser associado às habilidades de vencer e de ser capaz de administrar a própria carreira. A ideia de fracasso é produzida sob a forma do improdutivo, do estéril, da preguiça ou da desqualificação profissional. Ao mesmo tempo, contribui para a difusão das modas e modismos de gestão sem questionar ou desvelar o reducionismo e os condicionantes ideológicos embutidos em suas informações. Ou seja, "[...] o lucro é um excedente legítimo que não gera nem exploradores nem explorados, mas simplesmente ganhadores de um lado e malsucedidos ou perdedores do outro lado [...]" (AKTOUF, 2004 p. 68), e os empresários e dirigentes de empresas não mais representam símbolos da exploração do homem pelo homem, pelo contrário, transformam-se em símbolos do sucesso social.

Assim, os textos podem apresentar aspectos de controle social, em que realidade, ideologia e ficção se misturam e são disseminadas nas histórias de sucesso. Se, por um lado, o discurso da mídia de negócios acerca do empreendedorismo auxilia na redução de tensões geradas pela instabilidade do mundo do trabalho contemporâneo, por outro, contribui para a alienação e incorporação ingênua de modismos gerenciais, nada acrescentando a respeito das condições e relações de trabalho na contemporaneidade.

\section{Referências}

A ALAVANCA que move o mundo. HSM Management, São Paulo, p.60-66, set./out., 2007.

A CIDADE que se reinventou. Exame, São Paulo, p.54, abr., 2006.

A SOCIEDADE empreendedora. CartaCapital, São Paulo, p.61, abr. 2009.

AKTOUF, O. Governança e pensamento estratégico: uma crítica a Michael Porter. Revista de Administração de Empresas, v. 42, n. 3, jul./set., 2002.

Pós-Globalização, Administração e racionalidade econômica. São Paulo: Atlas, 2004.

ALVESSON, M.; DEETZ, S. Teoria crítica e abordagens pós-modernas para estudos organizacionais. In: CLEGG, S.; HARDY, C.; NORD, W. (Orgs.). Handbook de Estudos Organizacionais, v. 2, p. 227-266. São Paulo: Atlas, 1998.

; KARREMAN, D. Varieties of discourse: on the study of organizations through discourse analysis. Human Relations, v. 53, n. 9, p. 1125-1149, 2000.

BALBI, R. V. et al. Cultura Empreendedora: o que está sendo produzido na Administração? In: ENCONTRO NACIONAL DA ANPAD, 33, São Paulo, 2009. CD ROM Anais..., São Paulo: ANPAD, 2009.

BARROS, M. J. F.; PASSOS, E. S. Remando a favor da maré: racionalidade instrumental no curso de administração de empresas. Organização e Sociedade, v. 7, n. 19, p. 161-174, 2000. 
BILIONÁRIOS na marra. Exame, São Paulo, p.73-76, jun, 2008.

BOAVA, D. L. T.; MACEDO, F. M. F. Sentido axiológico do empreendedorismo. In: ENCONTRO ANUAL DA ANPAD, 33, São Paulo, 2009. CD ROM Anais..., São Paulo: ANPAD, 2009.

BOJE, D. Stories of the storytelling organization: a postmodern analysis of Disney as "Tamara-Land". Academy of Management Journal, v. 38, n. 4, Aug. 1995.

BOLTANSKI, L; CHIAPELLO, E. O novo espírito do capitalismo. São Paulo: Martins Fontes, 2009.

BORGES, J.; CASADO, T. Empreendedores no divã: entre o Heroic Economic Superman e o Sentient Self. In: ENCONTRO DA ANPAD, 33, São Paulo, 2009. CD ROM Anais..., São Paulo: ANPAD, 2009.

BYGRAVE, W.; HOFER, C. Theorizing about entrepreneurship. Entrepreneurship Theory and Practice, v. 16, n. 2 , p. 13-22, 1991.

CABEÇA de empresário. Você S.A., São Paulo, p.38-40, mai., 2008.

CANTILLON, R. Ensaio sobre a natureza do comércio em geral. Curitiba: Segesta Editora, 2002.

CARVAlHO, J. L. F. S.; CARVALHO, F. A. A.; BEZERRA, C.C. O monge, o executivo e o estudante ludibriado: uma análise empírica sobre leitura eficaz entre alunos de administração. Cad. EBAPE.BR, Rio de Janeiro, v. 8, n. 3, p. 537-549, 2010.

CASTANHAR, J. C. Empreendedorismo e desenvolvimento regional no Brasil: uma análise da relação entre a criação de empresas e o desenvolvimento regional ao longo do tempo e de estratégias de empreendedores selecionados. 2007. Tese (Doutorado) - Instituto Superior de Ciências do Trabalho e da Empresa, Escola de Gestão ISCTE, Portugal, 2007.

CENTRAL ÚNICA DOS TRABALHADORES; COMANDO GERAL DOS TRABALHADORES; FORÇA SINDICAL. Carta do Rio: educação e emprego no Brasil do próximo Milênio. Disponível em: <http://www.cinterfor.org.uy/public/english/region/ampro/cinterfor/temas/worker/youth/doc/dec_juv.htm>. Acesso em: 10 de out. 2010.

CHANLAT, J. F. Quais carreiras e para qual sociedade? Revista de Administração de Empresas, v. 35, n. 6, p. 67-75, 1995.

CONFEDERAÇÃO NACIONAL DA INDÚSTRIA. Educação para a nova indústria: sumário executivo. Disponível em:

<http://www.cni.org.br/portal/main.jsp?lumPageId=40288097122DE18801122F29B2BC0AAB\&itemId=8A9015D019

C8A3F10119CA23754D01F4\#Conteudo>. Acesso em: 22 abr. 2009.

COLBARI, A.L. A retórica do empreendedorismo e a formação para o trabalho na sociedade brasileira. SINAIS Revista Eletrônica, n. 1, v. 1, p. 75-111, 2007.

DESESPERADOS por enriquecer. Exame, São Paulo, p.60-65, jun., 2007.

DIAS, V.T. et al. Distinção entre as noções de empresária e 'empreendedora' na mídia de negócios: um estudo comparativo entre as revistas Exame e Fortune. In: ENCONTRO DA ANPAD, 31., Rio de Janeiro, 2007. CD ROM Anais..., Rio de Janeiro: ANPAD, 2007.

DO ZERO ao topo em 25 anos. Exame, São Paulo, p.19-25, set. 2006.

DORNELAS, J. C. A. Empreendedorismo: transformando idéias em negócios. Rio de Janeiro: Elsevier/Campus, 2008 . 
ECCEL, C. S.; GRISCI, C. L. I.; TONON, L. O corpo em revista: análise da apresentação do corpo em uma revista popular de negócios. In: ENCONTRO DA ANPAD, 31. Rio de Janeiro, 2007. Anais..., Rio de Janeiro: ANPAD, 2007.

EMPREENDEDOR do futuro. HSM Management, São Paulo, p.104-111, mar./abr., 2007.

EMPREENDEDORISMO no sangue. Carta Capital, São Paulo, p.52-54, set. 2009.

ENRIQUEZ, E. O indivíduo preso na armadilha da estrutura estratégica. Revista de Administração de Empresas, São Paulo, v. 37, n. 1, p. 18-29, jan./mar., 1997.

FAIRCLOUGH, N. Discurso e mudança social. Brasília: UnB, 2001.

FARIA, J.; MENEGHETTI, F. Discursos organizacionais. In: ENCONTRO DA ANPAD, 25., Campinas, 2001. Anais..., Campinas: ANPAD, 2001.

FEDERAÇÃO DAS INDÚSTRIAS DO ESTADO DO RIO DE JANEIRO. Conselho Empresarial de Jovens Empresários. Disponível em: <http://www.firjan.org.br/notas/cgi/cgilua.exe/sys/start.htm?infoid=7863\&sid=37>. Acesso em: 22 abr. 2009.

FILION, L. J. O empreendedorismo como tema de estudos superiores. Brasília: Universidade formando empreendedores, 1999.

FONSECA, F. A Grande imprensa e a constituição da agenda ultraliberal na Nova República. Estudos Históricos. CPDOC/FGV, n. 31, 2003.

FOUCAUlT, M. A Ordem do Discurso. 15. ed. São Paulo: Loyola, 2007.

GARTNER, W. Who is an entrepreneur? Is the wrong question. Entrepreneurship Theoryand Practice, v. 13, n. 4, p. 47-68, 1989.

GOMES, A. F. O empreendedorismo como uma alavanca para o desenvolvimento local. Revista de Administração de Empresas, v. 7, n. 2, jul./dez., 2005.

GRANT, D.; KEENOY, T.; OSWICK, C. Organizational Discourse. International Studies of Managment \& Organization, v. 31, n. 3, p. 5-24, 2001.

HARDY, C. Researching Organizational Discourse. International Studies of Managment \& Organization, v. 31, n. 3 , p. $25-47,2001$.

IPIRANGA, A. S. R.; FREITAS, A. A. F.; PAIVA, T. A. O empreendedorismo acadêmico no contexto da interação universidade - empresa - governo. Cad. EBAPE.BR, Rio de Janeiro, v. 8, n. 4, p. 687-693, 2010.

KETS DE VRIES, M. F. R. The entrepreneurial personality: person at the crossroads. Journal of Management Studies, v. 14, p. 24-58, 1977.

KORTEN, D. C. Quando as corporações regem o mundo. São Paulo: Futura, 1996.

KRUGER, N. F.; BRAZEAL, D. V. Entrepreneurial potential and potential entrepreneurs. Entrepreneurship Theory and Practice, v. 18, n. 3, p. 91-104, 1994.

LEITCH, S.; PALMER, I. Analysing texts in context: current practices and new protocols for critical discourse analysis in organization studies. Journal of Management Studies, v. 47, n. 8, p. 1194-1212, Sept. 2010.

LEMOS, A. H. C. Empreendedorismo no Brasil: uma atividade sem "espírito"? In: ENCONTRO NACIONAL DA ANPAD, 30., Brasília, 2005. CD ROM Anais..., Brasília: ANPAD, 2005. 
; RODRIGUEZ, D. A. Empregabilidade: conquista da autonomia profissional ou nova forma de submissão? In: ENCONTRO DE ESTUDOS ORGANIZACIONAIS DA ANPAD, 5., Belo Horizonte, 2008. CD ROM Anais..., Belo Horizonte: ANPAD, 2008.

LÓPEZ-RUIZ, O. Os executivos das transnacionais e o espírito do capitalismo: capital humano e empreendedorismo como valores sociais. Rio de Janeiro: Azougue Editorial, 2007.

LUMPKIN, G. T., DESS, G. G. Clarifying the entrepreneurial orientation construct and linking it to performance. Academy of Management Review, v. 21, n. 1, 135-172, 1996.

MARX, K.; ENGELS, F. Manifesto Comunista. São Paulo: CHED, 1980.

MCCLELLAND, D. C. The achieving society. Princeton: Van Nostrand, 1961.

A sociedade competitiva: realização e progresso social. Rio de Janeiro: Expressão e Cultura, 1972.

MEU NEGÓCIO é criar empresas. Exame, São Paulo, p.54-55, fev., 2008.

MICKLETHWAIT, J.; WOOLDRIDGE, A. Os bruxos da administração: como entender a babel dos gurus empresariais. Rio de Janeiro: Campus, 1998.

MINTZBERG, H. Strategy making in three modes. California Management Review, v. 16, n. 2, p. 44-53, 1973.

MISOCZKY, M. C. Pelo primado das relações nos estudos organizacionais: algumas indicações a partir de leituras enamoradas de Marx, Bourdieu e Deleuze. In: ENCONTRO NACIONAL DA ANPAD, 27, Atibaia, 2003. CD ROM Anais..., Atibaia: ANPAD, 2003.

NADA as detém. HSM Management, São Paulo, p.172-178, nov./dec., 2007.

NASSIF, V. M. J. et al. A universidade forma empreendedores? Aspectos convergentes e divergentes sob a ótica de alunos, professores, pais e empreendedores. In: ENCONTRO NACIONAL DA ANPAD, 32., Rio de Janeiro, 2008. CD ROM Anais..., Rio de Janeiro: ANPAD, 2008.

O MELHOR caminho para inovar. Exame, São Paulo, p.2-5, mar. 2006.

O PAÍS da mobilidade social. Exame, São Paulo, p.44-50, out., 2007.

OS ESTADOS UNIDOS dos empreendedores. Carta Capital, São Paulo, p.53-55, abr., 2009.

QUANTO mais melhor. Carta Capital, São Paulo, p.55-56, abr., 2009.

QUINTETO inovador. Você S.A., São Paulo, p.42-45, abr. 2006.

RIBEIRO, D. A.; SACRAMENTO, A. R. S. Ensino e currículo em administração: a opção brasileira. Revista Gestão e Planejamento, v. 10, n. 2, jul./dez., p.193-205, 2009.

RODRIGUES, A. L.; MORIN, E.; STREHLAU, S. A imagem de executivos na mídia: um estudo com jornais de Québec. Cad. EBAPE.BR, Rio de Janeiro, v. 7, n. 2, p. 236-251, 2009.

SANTOS, B. S. Do pós-moderno ao pós-colonial. E para além de um e outro. In: CONGRESSO LUSO-AFROBRASILEIRO DE CIÊNCIAS SOCIAIS, 7. Conferência de Abertura, Coimbra, 2004.

SANTOS, L. G. Apresentação. In: LÓPEZ-RUIZ. Os executivos das transnacionais e o espírito do capitalismo: capital humano e empreendedorismo como valores sociais. Rio de Janeiro: Azougue Editorial, 2007. 
SARAIVA, L. A. S. O túnel no fim da luz: a educação superior em administração no Brasil e a questão da emancipação. In: ENCONTRO NACIONAL DA ANPAD, 31., Rio de Janeiro, 2007. CD ROM Anais..., Rio de Janeiro: ANPAD, 2007.

SCHRAMM, C.; LITAN, R. E. The growth solution. The American, p. 32-38, July/Aug., 2008.

SCHUMPETER, J. Capitalismo, Socialismo e Democracia. 1. ed. brasileira. Rio de Janeiro: Editora Fundo de Cultura, 1961.

Fundamentos do Pensamento Econômico. Rio de Janeiro: Zahar, 1968.

. A Teoria do Desenvolvimento Econômico. São Paulo: Nova Cultural, 2001.

SOUZA, E. C. L.; DEPIERI, C. C. L. S. Cultura e atitude empreendedora: um estudo em empresas do Distrito Federal. FACES, v. 6, n. 3, set./dez., 2007.

.; SOUZA, C. C. L. Uma nova maneira de refletir os conceitos de cultura, empreendedorismo e inovação: uma metodologia de vida. In: ENCONTRO NACIONAL DA ANPAD, 32, Rio de Janeiro, 2008. CD ROM Anais..., Rio de Janeiro: ANPAD, 2008.

STEFFY, B. D.; GRIMES, A. J. A critical theory of organization science. Academy of Management Review, v. 11, n. 2, p. 322-336, 1986.

TERRAS de oportunidades. Carta Capital, São Paulo, p.57-58, abr., 2009.

TONELLI, D. F.; BRITO, M. J.; ZAMBALDE, A. L. Empreendedorismo na ótica da teoria ator-rede: explorando alternativa às perspectivas subjetivista e objetivista. Cad. EBAPE.BR, Rio de Janeiro, v. 9, Edição Especial, p.586-603, 2011.

UMA IDEIA que amadureceu. CartaCapital, São Paulo, p.50-53, abr. 2009.

VISIONÁRIO ou maluco? Exame, São Paulo, p.48-52, mar., 2008.

WOOD JR., T. Organizações espetaculares. Rio de Janeiro: Editora FGV, 2001.

; PAUlA, A. P. P. Pop-Management. In: ENCONTRO NACIONAL DA ANPAD, 25, Campinas, 2001. CD ROM Anais... Campinas: ANPAD, 2001.

; PAUlA, A. P. P. A mídia especializada e a cultura do management. Organizações \& Sociedade, v. 13, n. 38, 91-105, 2006.

ZAMPIER, M. A.; TAKAHASHI, A. R. W. Competências empreendedoras e processos de aprendizagem empreendedora: modelo conceitual de pesquisa. Cad. EBAPE.BR, Rio de Janeiro, v. 9, Edição Especial, p. 565-585, 2011. 